\title{
ASSESSING IMPACTS OF CLIMATE CHANGE ON TEAK AND SAL LANDSCAPE USING MODIS TIME SERIES DATA
}

\author{
M. K. Patasaraiya ${ }^{1 *}$, B. Sinha ${ }^{2}$, J. Bisaria ${ }^{1}$, S. Saran ${ }^{3}$, and R.K. Jaiswa ${ }^{4}$ \\ ${ }^{1}$ Indian Institute of Forest Management, Bhopal, India - mpatsariya@gmail.com,jigyasa@iifm.ac.in \\ ${ }^{2}$ Indian Institute of Forest Management, Bhopal - bhaskarsinha@hotmail.com \\ \& School of Ecology and Environment Studies, Nalanda University, Rajgir, Bihar \\ ${ }^{3}$ Indian Institute of Remote Sensing, Dehradun, India-saran@iirs.gov.in \\ ${ }^{4}$ Indian Space research Organisation, Bangalore, India-rajeev_jnu@hotmail.com
}

\section{Commission V, SS: Natural Resources Management}

KEY WORDS: Climate Change Impact, NDVI, Phenology, Satpura Tiger Reserve

\begin{abstract}
:
Climate change poses a severe threat to the forest ecosystems by impacting its productivity, species composition and forest biodiversity at global and regional level. The scientific community all over the world is using remote sensing techniques to monitor and assess the impact of climate change on forest ecosystems. The consistent time series data provided by MODIS is immensely used for developing a different type of Vegetation indices like NDVI (Normalized difference vegetation indices) products at different spatial and temporal resolution. These vegetation indices have significant potential to detect forest growth and health, vegetation seasonality and different phenological events like budding and flowering. The current study aims to understand the impact of climate change on Teak and Sal forest of STR (Satpura tiger reserve) in central India by using Landsat and MODIS time series data. The rationale for taking STR as study site was to attribute the changes exclusively to climate change as there is no anthropogenic disturbance in STR. A change detection analysis was carried out to detect changes between the period 2017 and 1990 using Landsat data of October month. To understand the inter-annual and seasonal variation of Teak and Sal forests, freely available MOD13Q1 product (250m, 16 days' interval) was used to extract NDVI values for each month and four seasons (DJF, JJAS, ON, MAM) for the period 2000 to 2015. The climatic data (rainfall and temperature) was sourced from IMD (India Meteorological Department) at different resolutions (1, 0.5 and 0.25 degree) for the given period of the study. A correlation analysis was done to establish a causal relationship between climate variable (temperature and rainfall) and vegetation health (NDVI) on a different temporal scale of annual, seasonal and month. The study found an increasing trend in annual mean temperature and no consistent trend in total annual rainfall over the period 2000 to 2015 . The maximum percentage change was observed in minimum temperature over the period 2000 to 2015. The average annual NDVI of Teak and Sal forests showed an increasing trend however, no trend was observed in seasonal and monthly NDVI over the same period. The maximum and minimum NDVI was found in the post-monsoon months $(\mathrm{ON})$ and summer months (MAM) respectively. As STR is a Teak and Sal dominated landscape, the findings of the current study can also be applied in developing silvicultural and adaptation strategies for other Teak and Sal dominated landscapes of central India.
\end{abstract}

\section{INTRODUCTION}

Climate change is one of the most severe problems impacting humanity across the globe and therefore it has necessitated all governments to tackle this challenge on priority. Furthermore, it requires commitment from all countries to reduce/mitigate the impact by reducing their emissions of green-house gases. The world is facing severe consequences in form of increased frequency of natural disasters, increased sea level rise, changed rainfall pattern, lowered agricultural productivity, retreated glaciers and temperature anomalies with a pronounced effect on developing countries (Schär, 2004; Dasgupta et al., 2009; Olesen et al., 2002; Kaser et al., 2004; Hansen et al., 2010; Stern, 2007; IPCC, 2014). Forests have the potential in slowing down the current trend of global warming by sequestering $\mathrm{CO}_{2}$ from the atmosphere. The world's forests absorb as much as $30 \%$ of annual global anthropogenic $\mathrm{CO}_{2}$ emissions (Bellassen \& Luyssaert, 2014). However, it has been observed that tropical forests are vulnerable to climate change and the impacts on them could be so severe as to threaten their structure, function and services (Betts et al. 2008). The fourth assessment report of IPCC concluded that forest ecosystems could be seriously

impacted by future climate change, even with the moderate global warming of $1{ }^{\circ} \mathrm{C}$ to $2^{\circ} \mathrm{C}$ (IPCC, 2007). This will reduce the capacity of forests to supply ecological services and to support millions of people, which implies that forest resource is one of the priority sectors to understand the impact of climate change for not only securing livelihoods and ecosystem services but also as adaptation and mitigation measures to climate change. There are different types of techniques available to assess the impacts of climate change on the forest ecosystem reported from different parts of the world. Remote sensing is one of the potential tools to monitor the vegetation dynamics with respect to climate variables. Consistent Normalized Difference Vegetation Index (NDVI) time series are widely applied to monitor forest resources and used to investigate the interactions between climate and forest ecosystems (Beck et al., 2007; Guo et al., 2007). NDVI is related to biophysical variables, such as leaf area, canopy coverage, productivity and chlorophyll density

\footnotetext{
${ }^{*}$ Corresponding author
} 
as well as to vegetation phenology (Spanner et al., 1990) and can reflect vegetation growth status. In India, there is lack of studies which used MODIS time series data to assess the impact of climate change at the species level. Temperature and precipitation are the most important climatic factors that contribute to temporal and spatial variation in vegetation (Bachelet et al. 2001; Kawabata, Ichii, and Yamaguchi 2001). Such impacts on vegetation characteristics also vary with the type of forest and its species characteristics and composition (Schultz and Halpert 1993, 1995; Suzuki, Xu, and Motoya 2006; Song and Ma 2011). Thus, it is important to understand and quantify the relationship between climatic variables and important species of a forest to assess the resilience potential of forest and its species, so that future silvicultural management can be prescribed. With this rationale, the study attempts to understand the past climatic trend of 45 years in STR using climate variable datasets for temperature and rainfall. The study also aims to understand the causal relationship between vegetation health of Teak and Sal landscape with climate variables using correlation analysis for the period 2000-2015.

\section{METHODOLOGY}

\subsection{Study Area}

Satpura Tiger Reserve (STR) is situated in Hoshangabad district of Madhya Pradesh in Central India (Fig.1a). The coordinate of the study site is $22^{\circ} 19^{\prime} 28^{\prime \prime} \mathrm{N}$ to $22^{\circ} 45^{\prime} 30^{\prime \prime} \mathrm{N}$ latitude and $77^{\circ}$ $53^{\prime} 48^{\prime \prime} \mathrm{E}$ to $78^{0} 34^{\prime} 0$ " E longitude. STR comprises three protected areas (PAs) namely, SNP (Satpura National Park), Bori sanctuary and Pachmarhi sanctuary. The total area extends almost over an area of $600 \mathrm{~km}^{2}$ which also makes it the largest tiger reserve of Madhya Pradesh. There are total of ten forest ranges in STR including six core and four buffer ranges (Fig.1b). STR is mainly dominated by miscellaneous forest with two of its core ranges, namely Bori and Churna are dominated by Teak forest and East and West Pachmari ranges are dominated by Sal forest (Fig.1c). There are total of 476 forest compartments without grassland and water compartments in the six core ranges of STR in which Teak and Sal are dominated in 209 and 27 compartments respectively. In the present study, the observations with respect to vegetation were confined to the core zone of STR because the study deals with the impact of climate variables viz rainfall and temperature on vegetation growth which requires only undisturbed forest with no or very little anthropogenic disturbance during last 30 year of time so that the changes measured can be attributed exclusively to climate change.

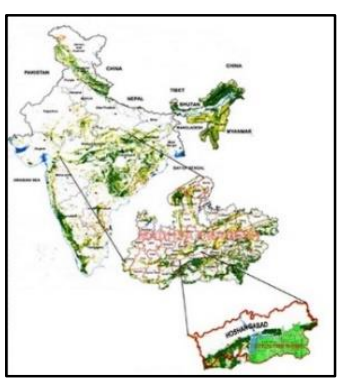

(a)

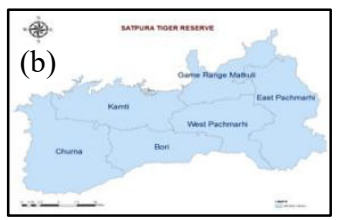

(c)

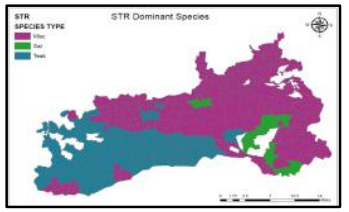

Fig. (1a) Location map of STR; (1b) Core ranges of STR and (1c) Dominant species in each compartment of STR

\subsection{Details of climate and remote sensing datasets used in the study}

\subsubsection{Climate Data}

The climate variable datasets for temperature and rainfall were sourced from the Indian Meteorological Department (IMD). To estimate an overall trend of climate in the study area, the gridded dataset of temperature and rainfall available for highest resolution was analyzed for the period of 1970 to 2015, respectively. The daily mean temperature and daily rainfall data were analyzed for the monthly mean temperature and total annual rainfall, respectively. The study also attempts to understand the causal relationship between vegetation health (NDVI) and climate variable for the period between 2000 to 2015. In this regard, the climate data (MinT, MaxT, MeanT and rainfall) was also analyzed for the period between 2000-2015 for correlation analysis.

\subsubsection{Remote Sensing Data}

Different type of remote sensing products and imageries were used to assess the past change of vegetation for different time periods. Land use land class (LULC) change analysis was done using supervised classification with the help of October month imageries of Landsat (Table. 1). Similarly, to assess the change at compartment level, Landsat imageries for October months was used for the period 1990 and 2016. Time series analysis was done using the freely available MOD13Q1 product, which is available from 2000 to till date with an interval of 16 days at $250 \mathrm{~m}$ resolution (Table. 1 )

Table.1 Details of the remote sensing data used in the study

\begin{tabular}{|l|l|l|l|l|}
\hline Sensor & Source & Product & Resolution & $\begin{array}{l}\text { Time } \\
\text { period }\end{array}$ \\
\hline Landsat & $\begin{array}{l}\text { Earth } \\
\text { Explorer; } \\
\text { USGS }\end{array}$ & $\begin{array}{l}\text { Landsat-5 } \\
\text { (TM) }\end{array}$ & $30 \mathrm{~m}$ & $\begin{array}{l}1990 \\
\text { October }\end{array}$ \\
\hline Landsat & $\begin{array}{l}\text { Earth } \\
\text { Explorer; } \\
\text { USGS }\end{array}$ & $\begin{array}{l}\text { Landsat-8 } \\
\text { (OLI) }\end{array}$ & $30 \mathrm{~m}$ & $\begin{array}{l}2016 \\
\text { October }\end{array}$ \\
\hline MODIS & $\begin{array}{l}\text { Earth } \\
\text { Explorer } \\
\text { MODIS } \\
\text { LP DAAC } \\
\text { NASA }\end{array}$ & $\begin{array}{l}\text { MOD13Q1 } \\
\text { 16-day } \\
\text { composite } \\
\text { NDVI }\end{array}$ & $250 \mathrm{~m}$ & $\begin{array}{l}2000 \mathrm{TO} \\
2015 \\
\text { (Each } \\
\text { Month) }\end{array}$ \\
\hline LISS-IV & $\begin{array}{l}\text { MP Forest } \\
\text { Dept. }\end{array}$ & & $23.5 \mathrm{~m}$ & 2014 \\
\hline
\end{tabular}

\subsection{Land Use Land Cover (LULC) Change and NDVI Based Change Analysis}

To compute the changes in the area of different land use classes, a LULC change analysis was done using a supervised 
classification method. The changes in the area of different land use were calculated using maximum likelihood classification method in ArcGIS 10.4 for the period between 1990 and 2016. The LISS-IV imagery was used for training the samples of different land use and ground truthing. To assess the changes at compartment level, a MODIS NDVI based change analysis was done. NDVI values were extracted for each compartment and the difference in NDVI values was grouped into five groups and plotted in compartment shape file. The steps used in the analysis are given in the flowchart (Fig. 2).

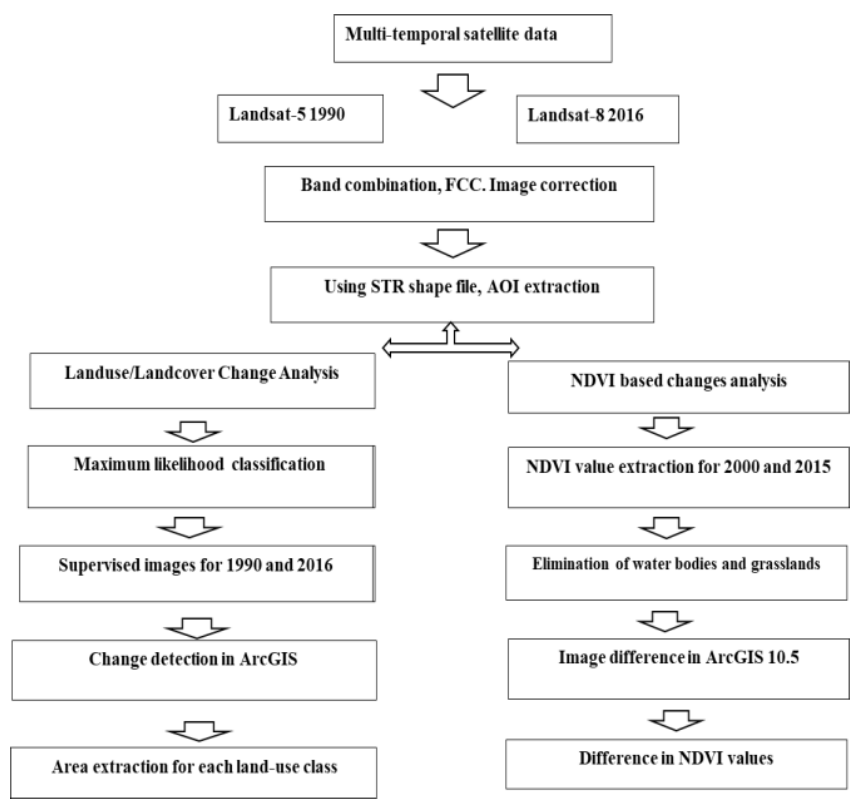

Fig.2 Flowchart of steps used in LULC and NDVI based change detection analysis

\subsection{MODIS Time series extraction}

In order to monitor the vegetation health, the consistent time series data available from MODIS onboard Terra satellite has been widely used in different climate change studies at global and regional scale. In this study, the freely available MOD13Q1 product was processed for extracting NDVI values for all compartments of the core area of STR for the period 2000 to 2015. The extracted values of NDVI were grouped for Teak and Sal dominated compartments. The steps used in the extraction of NDVI values for each compartment is given below in Fig. 3.

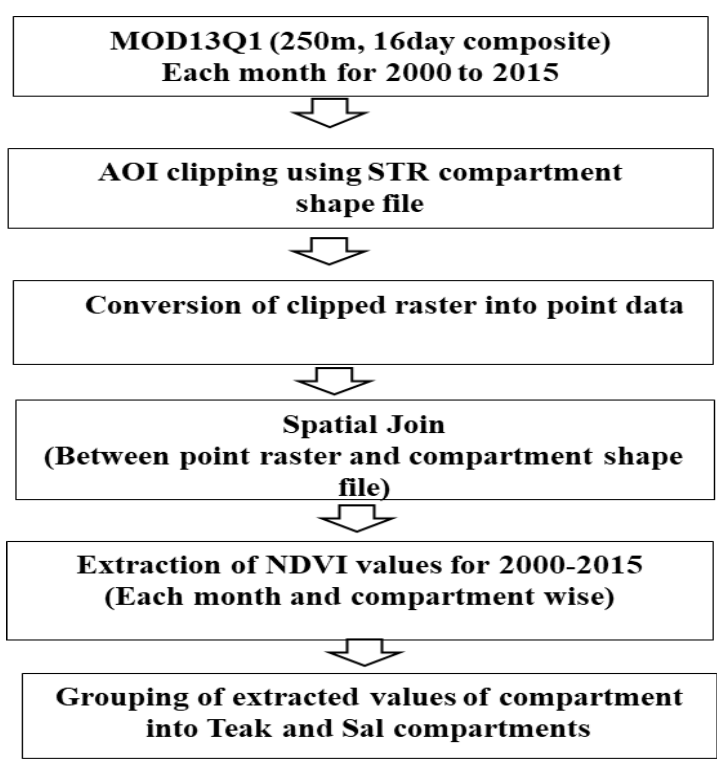

Fig. 3. Flowchart of the NDVI extraction process

\section{RESULTS AND DISCUSSION}

\subsection{Climate Data Trend Analysis (1971-2015)}

The gridded climate data procured from IMD were analysed to understand the overall trend of climate in STR in the past 45 years (1970-2015). In this regard, two climate variables (mean annual temperature and total annual rainfall) were analysed for the 1970-2015 (45 years). The mean annual temperature computed for the last 45 years was 24.86 degree Celsius and also showed a significant increasing trend $(\mathrm{P}=0.3)$ (Fig.4). The last decade (2000-2010) showed maximum warming and was significantly higher than the three previous decades, however, there was no significant difference in the mean temperature during the first three decades (Fig.5). The total annual rainfall over the period of 45 years showed no trend of increase or decrease and a similar observation was also recorded for a number of rainy days (Fig. 6). Number of rainy days and mean annual rainfall for 45 years was found to be 103 days and $1115.58 \mathrm{~mm}$, respectively. The highest annual rainfall was observed in the year 1999, followed by 1979 . 


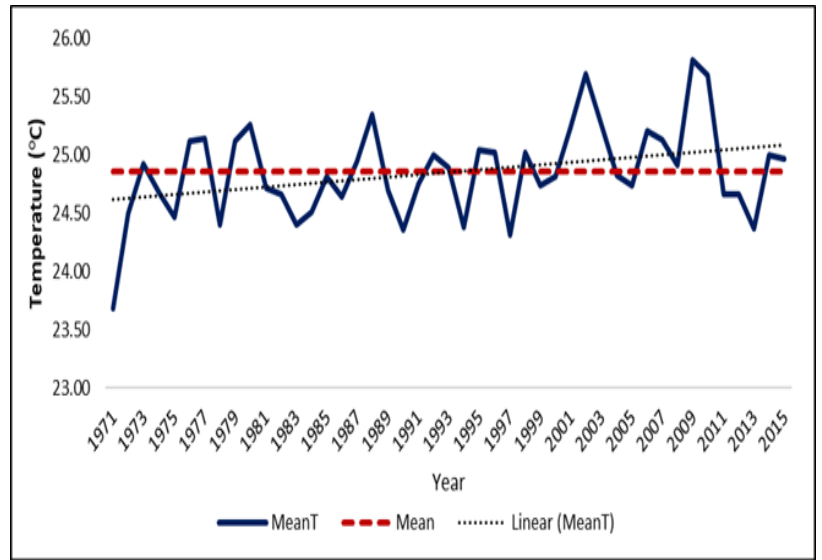

Fig. 4 Average mean annual temperature of STR (1970-2015)

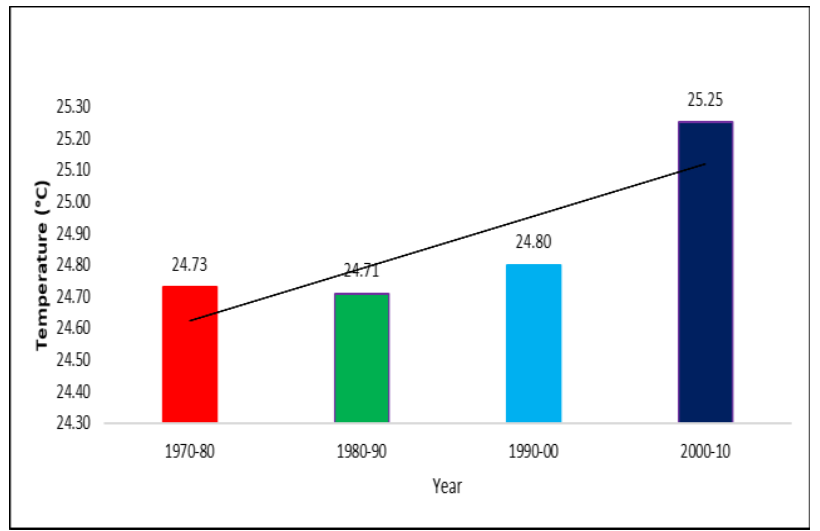

Fig. 5. Decadal mean temperature in STR (1970-2010)

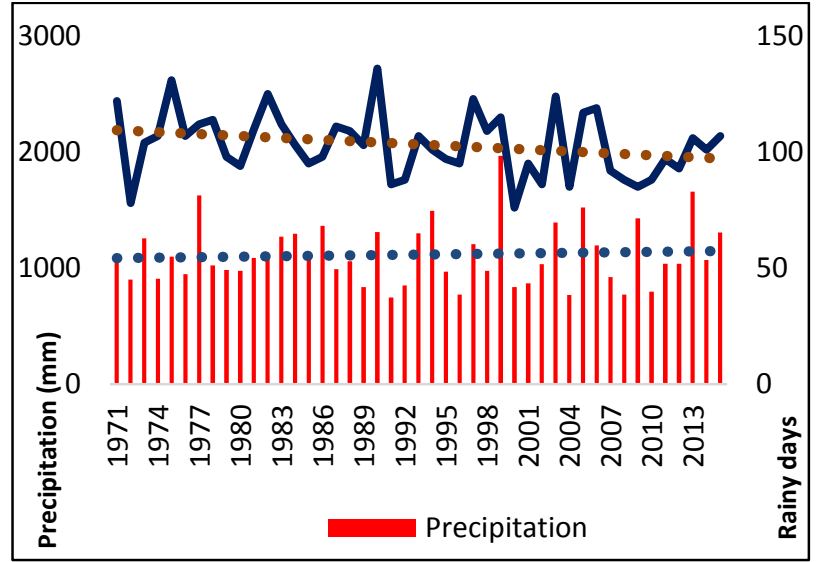

Fig.6 Rainfall and number of rainy days in STR (1970-2015)

\subsection{Climate Data Time Series Analysis (2000-2015)}

The past climate data for only sixteen years (2000-2015) is analyzed so that the same can be compared with extracted NDVI from the MODIS data, which is available from 2000 to till date. Since the study intends to understand the impact of climate change on forest using NDVI, the data available of a common period (2000-2015) are considered for analysis.
3.2.1 Temperature Data (2000-2015): The datasets of minimum, maximum, mean temperatures and rainfall were analyzed for a period between 2000 and 2015. The average minimum, mean and maximum temperature of sixteen years were $18.23^{\circ} \mathrm{C}, 25.32^{\circ} \mathrm{C}$ and $31.98^{\circ} \mathrm{C}$ for STR. The trends of annual mean temperature did not show any positive or negative trend over the same period. The percentage deviation of annual means of MinT (minimum temperature), MaxT (maximum temperature) and MeanT (mean temperature) were calculated from the overall mean of 16 years (2000-2015) (Fig.7).

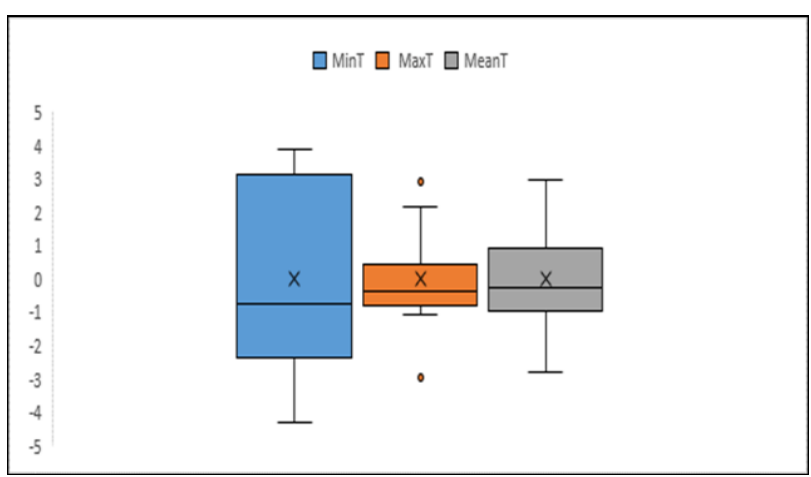

Fig.7 Percent changes in annual temperatures of STR

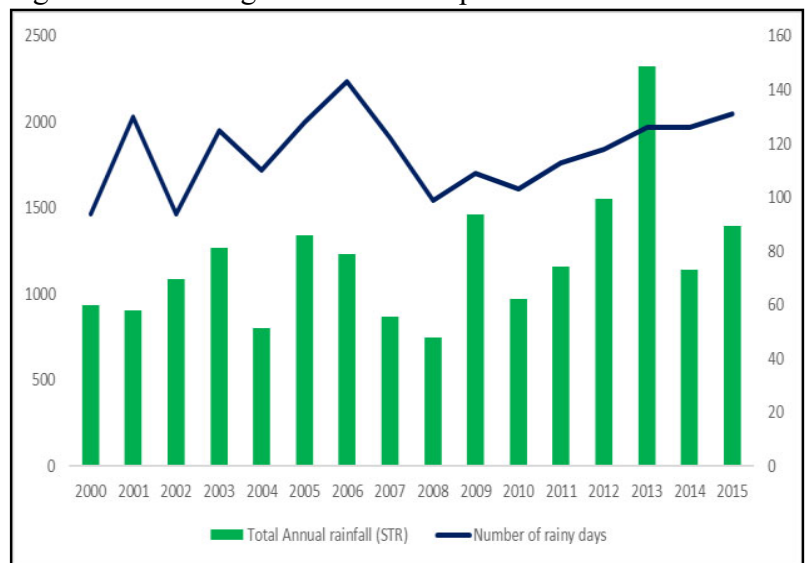

Fig.8 Total annual rainfall and number of rainy days in STR (2000-2015)

\subsubsection{Rainfall Data (2000-2015)}

The daily rainfall data was analyzed for total annual rainfall and total number of rainy days for STR for the period from 2000 to 2015. STR received most of its rainfall in the months of southwest monsoon i.e. June, July, August and September. The total annual rainfall varied from its 16-year average behaviour in STR. The number of years with higher annual rainfall as compared to mean of 16years annual rainfall was more in STR. Total number of rainy days showed an increasing trend for the same time period. The average number of rainy days was 117 with a maximum in 2006 (143 days) and minimum in 2001 (94 days) for the period 2000-2015.(Fig.8)

\subsection{Change in Land Use Land Cover}

The change in land use/land cover (LULC) was analyzed using a supervised classification method with ArcGIS 10.4 software (Fig.9 (a \& b). A maximum likelihood classification (MLC) was used to assess the nature of changes and to determine the areal 
extent and spatial pattern of those changes in different LULC. The change was calculated using Landsat imageries of October month of 2016 and 1990. FSI (Forest Survey of India) classification of LULC was used to categorize different land use and type of forest. In the current study, five different land use (Water bodies, grassland/agriculture, low dense forest, Moderate dense forest and Very dense forest) are identified and their change over time have been analyzed. To corroborate the accuracy of pixel selection of different land class, a highresolution imagery of LISS-IV was used. The change in the area of the five categorized LULC of STR for 2016 and 1990 is shown in form of pie chart (Fig. 10 (a \& b ). There was an increase in the area of water bodies in the study area. The area of open forest reduced which is indicative of a reduction of anthropogenic pressure from the forest due to village relocations. There is an increase of dense forest in STR from open forest

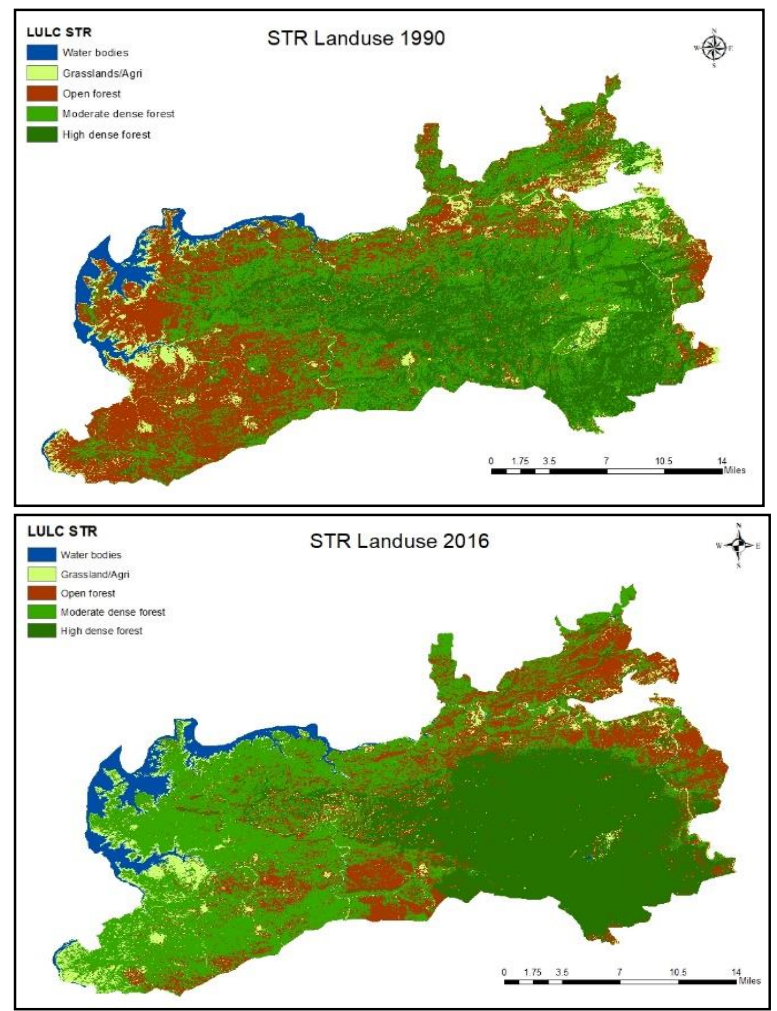

Fig. 9 LULC maps of STR (a) 1990 (b) 2016

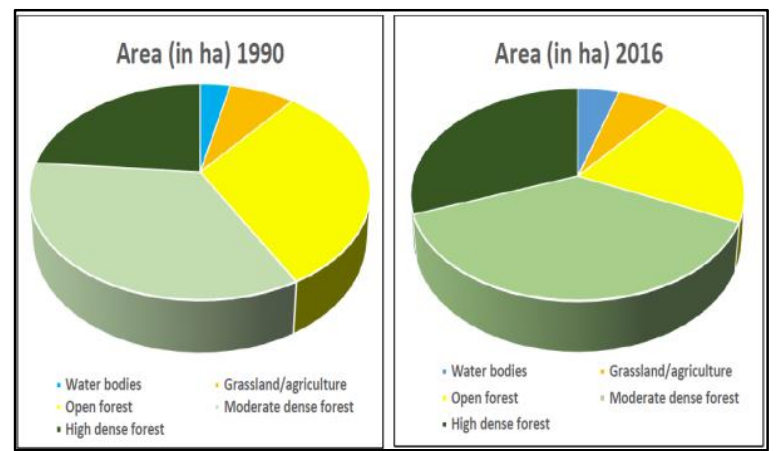

Fig.10 Pie chart representing the change in the area of different LULC (a)1990 (b) 2016

\subsection{MODIS NDVI Based Change Detection}

A change detection analysis was done using the pixel by pixel difference method in NDVI values between 2000 and 2015 for each compartment of the core zone of STR for the month of October. The computed change of each compartment was further classified into five classes which ranged from -0.32 to +0.27 (Fig.11).

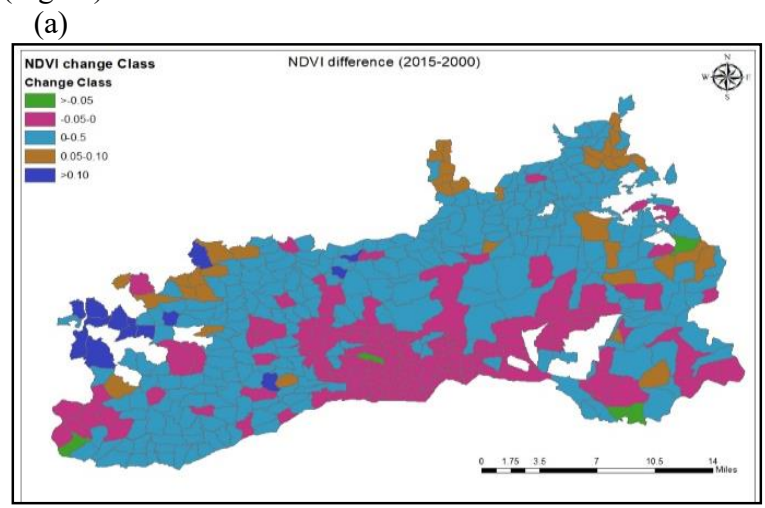

(b)

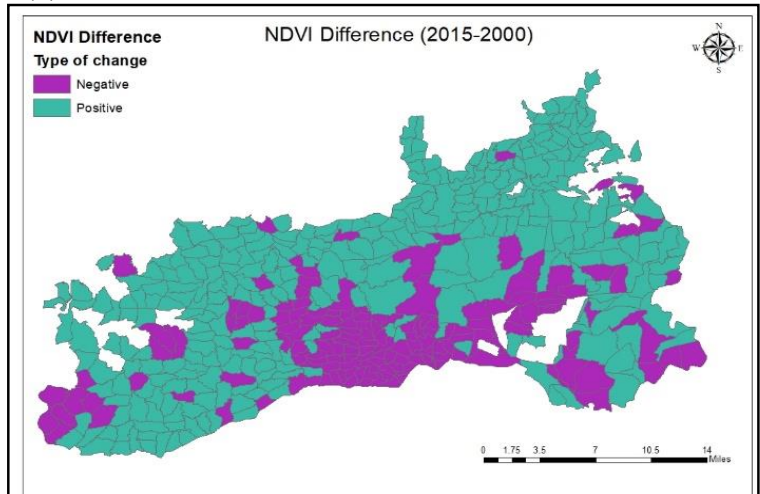

Fig.11 MODIS NDVI Based Changes (a) Type of change (b) Class wise

Most of the compartments of Churna and Bori ranges showed positive change implying the increase in vegetation health during 1990 and 2016 whereas most of Sal dominated compartments showed a decline in their NDVI values which could be attributed to an increased infestation of Sal borer in the area. This is, in contrast, to the increase in the high dense forest in pachmari ranges in the above discussed LULC analysis. The increased infestations of Sal borer could be due to increased temperature and reduced rainfall in the area. Most of the compartments change ranged from -0.05 to 0 and 0 to +0.05 NDVI values.

\subsection{MODIS Time Series Analysis (2000-2015)}

To assess the trends and dynamics of Teak and Sal forests, it was required that data is extracted for each forest compartment and studied at a finer granularity to examine the causal relationship between climatic factors like temperature and rainfall with vegetation dynamics/health. In this study, NDVI was used as proxy indicators, which have been used by scientific communities all over the world (Pettorelli et al., 2005). The monthly average values of NDVI for Teak and Sal forest 
compartments were extracted using image processing program and are aggregated on monthly, the seasonal and annual level for Teak and Sal dominated compartments of STR. The trends of annual mean NDVI for Teak and Sal forests showed similar which is also a year of excessive rainfall. The excess rainfall observed during the rainy months of 2013 could have resulted in high cloud cover which in turn could have affected the NDVI over the study area.

In order to see the seasonal changes of vegetation growth, extracted NDVI values were grouped into four seasons i.e. monsoon (JJAS), pre-monsoon (MAM), post-monsoon (ON) and winter (DJF). In general, the NDVI of Sal forests was higher as compared to the Teak forest in all seasons [Fig. 14 (a-d)]. The maximum value of NDVI was observed in Post monsoon season $(\mathrm{ON})$ and the minimum value was observed in pre-monsoon (MAM) for both Teak and Sal forests of STR. Monthly averages of NDVI of Teak and Sal are given in Fig. 13. Maximum NDVI values were reported in the month of September for Sal as well as Teak forest. Post monsoon, the forest becomes lush green due to the presence of fully expanded leaves of trees and shrubs and a dense herbaceous layer resulting in maximum NDVI values in the month of September after the rainy season. Minimum NDVI of Teak and Sal forest was observed in the month of April and July respectively. This corresponds to the shedding of Teak leaves which starts from December and completes in the month of April. Whereas, for Sal forests, NDVI was minimum in July because of its semi-evergreen nature. Additionally, the reason behind minimum NDVI values in July could be attributed to rainfall which causes more clouds to appear and then reduces incident radiation. Limited incident radiation hinders photosynthesis which is essential for vegetation growth (Song and Ma, 2008) which ultimately reduces NDVI values. There are many studies comparing NDVI and EVI for their discerning ability to detect seasonal and phenological changes which conclude EVI as a better indicator in high canopy areas because NDVI gets asymptotically saturated in high biomass regions (Heaute et al., 2002, Yang et al., 2007 and Chang et al, 2014). Thus, in order to study the vegetation dynamics in terms of seasonal and phenological changes, it is important to use both NDVI and EVI. trend of increase between the period 2000 to 2015 (Fig. 12). Further, reduced NDVI values were reported in the year 2013,

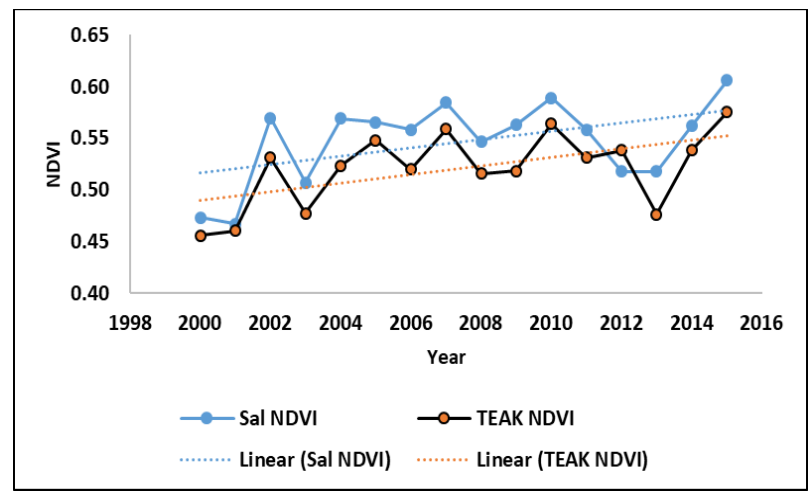

Fig. 12 Mean Annual NDVI of Teak and Sal forest

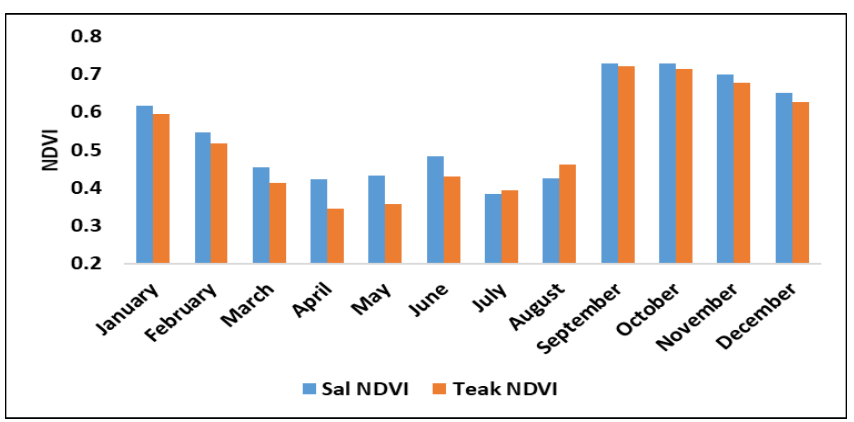

Fig. 13 Monthly average NDVI of Teak and Sal forest

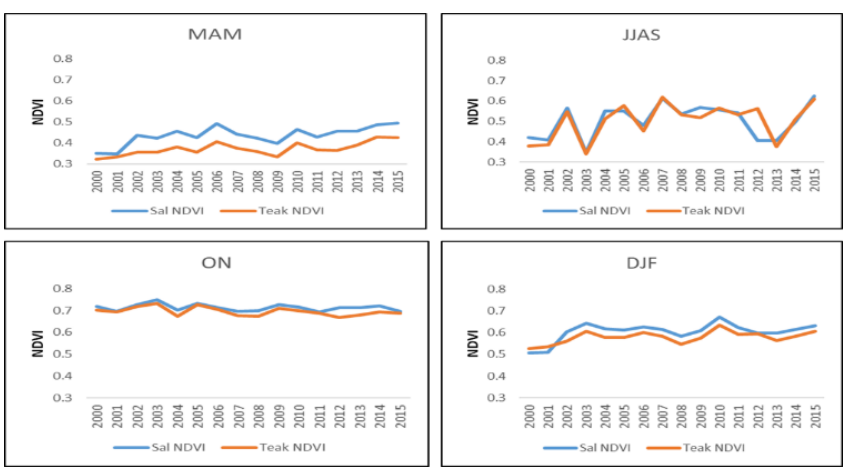

Fig. 14 (a-d) Seasonal NDVI of Teak and Sal forest a) DJF b) JJAS c) MAM d) ON

\section{CORRELATION}

The study attempts to understand the causal relationship between climate variables (MinT, MaxT, MeanT and rainfall) with vegetation health indicator NDVI for Teak and Sal landscape for the period 2000 to 2015 . A correlation analysis was done using SPSS and R software on annual and seasonal granularity. The main objective of correlation analysis between annual means of climate variables and NDVI of Teak and Sal forest is to identify climatic variables that influence vegetation health for the same period. There are several studies that have correlated climate variable with NDVI; however, the correlations derived in these studies are both positive or negative indicating the contextual relationship among these variables depending on climate and vegetation type of study area (Hao, 2012; Nischita et al., 2014). Type of vegetation and other topographic factors like snow cover, slope and soil type influence the magnitude and type of correlation.

\subsection{Correlation Between Annual Means}

The correlation coefficients were calculated between annual means of NDVI of Teak and Sal forests with climate variables (MinT, MaxT, MeanT and rainfall) for the time period between 2000 and 2015 (Table 2). Though statistically insignificant, a positive correlation was observed between Teak and Sal NDVI with MaxT and MeanT, while a negative correlation was observed between Teak and Sal NDVI and MinT and rainfall. The maximum correlation was found between Teak NDVI and maximum temperature and Sal NDVI with Mean temperature implying sensitivity of Teak forest to maximum temperature and Sal forest to mean temperature. Thus, we could conclude that 
both the species are sensitive to change in temperature with Sal more sensitive to mean temperature, whereas Teak is more sensitive to change in maximum temperature.

Table. 2 Annual correlations (2000-2015)

\begin{tabular}{|l|l|l|l|l|}
\hline & MaxT & MinT & MeanT & Rainfall \\
\hline Teak NDVI & 0.57 & -0.19 & 0.31 & -0.10 \\
\hline Sal NDVI & 0.05 & -0.09 & 0.36 & -0.07 \\
\hline
\end{tabular}

The above analysis infers on relations of aggregate (annual) climatic variables and aggregate vegetation health indicators. For a more contextual analysis, the relationships have to be examined in distinct seasons in the study area. Thus, correlation analysis was done between seasonal climate variables and vegetation health indicator NDVI.

\subsection{Correlation Between Seasonal Means}

Climate data and NDVI were aggregated into four distinct seasons, i.e., pre-monsoon (MAM), monsoon (JJAS), postmonsoon (ON) and winter (DJF) of the study area. The correlation was computed for all seasons of Teak and Sal forest of STR (Table. 3). Overall, NDVI of both Teak and Sal landscapes showed a similar type of correlation (positive or negative) in different seasons

4.2.1 Pre-monsoon (MAM): In MAM, a significantly strong negative correlation was found in between Teak NDVI and all temperatures (MinT, MaxT and MeanT) whereas in case of Sal NDVI the correlation was not significant. This indicates the sensitivity of Teak forest to variation in temperature in the summer season. The Sal forest showed resilience towards the changes in temperature of the summer season. The rainfall was found significant and positively correlated with both Teak and Sal NDVI. (Table. 3)

4.2.2 Monsoon (JJAS): In monsoon months (JJAS), NDVI of Teak and Sal forests was weak and positively correlated with temperatures except in case of minimum temperature which was significant and negatively correlated with Teak and Sal NDVI. This corresponds to field conditions of the rainy season, as, in JJAS season, minimum temperature decline and NDVI of Teak and Sal increases in the month of August and September due to flush after rainfall resulting in a negative correlation. Chang et al. (2014) and Sarmah et al. (2018) also reported the similar type of correlations during the monsoon season (JJAS) in forest areas. (Table. 3)

4.2.3 Post-monsoon (ON): The post-monsoon months of October and November correspond to maximum values of NDVI in both teak and Sal forest. This could be attributed to sustained soil moisture of rainy months and increased leaf area index (Nischita et al., 2014, Chang et al., 2014). Both Teak and Sal NDVI was significant and positively correlated with the temperatures except the correlation with minimum temperature was not significant. The correlation with rainfall was positive and insignificant in both Teak and Sal NDVI. (Table. 3)
4.2.4 Winter (DJF): In winter months, the NDVI of Teak and Sal forests show a declining trend, which could be attributed to early shedding of leaves in Teak and Sal forest that starts from the month of December and January (Singh and Kushwaha, 2005). The same has been also observed in the field and in discussion with forest officials. In compare of post-monsoon months, winter months shows an increasing trend in temperatures especially in the month of February. Therefore, the NDVI of Teak and Sal forest (decreasing) was found significant and negatively correlated with increasing temperatures. The correlation with rainfall was found to be weak and insignificant with both Teak and Sal NDVI (Table. 3)

Table. 3 Seasonal Correlations Between Teak and Sal NDVI with Climate Variables

\begin{tabular}{|l|l|l|l|l|l|}
\hline Season & & MaxT & MinT & MeanT & Rainfall \\
\hline \multirow{2}{*}{ DJF } & $\begin{array}{l}\text { Teak } \\
\text { NDVI }\end{array}$ & $-.520^{* *}$ & $-.485^{* *}$ & $-.549^{* *}$ & 0.034 \\
\cline { 2 - 6 } & $\begin{array}{l}\text { Sal } \\
\text { NDVI }\end{array}$ & $-.479^{* *}$ & $-.382^{* *}$ & $-.473^{* *}$ & 0.104 \\
\hline \multirow{2}{*}{ MAM } & $\begin{array}{l}\text { Teak } \\
\text { NDVI }\end{array}$ & $-.586^{* *}$ & $-.558^{* *}$ & $-.571^{* *}$ & $.490^{* *}$ \\
\cline { 2 - 6 } & $\begin{array}{l}\text { Sal } \\
\text { NDVI }\end{array}$ & -0.238 & -0.247 & -0.234 & $.409^{* *}$ \\
\hline \multirow{5}{*}{ JJS } & $\begin{array}{l}\text { Teak } \\
\text { NDVI }\end{array}$ & 0.041 & $-.326^{* *}$ & 0.114 & $-.378^{* *}$ \\
\cline { 2 - 6 } & $\begin{array}{l}\text { Sal } \\
\text { NDVI }\end{array}$ & 0.202 & -0.211 & 0.031 & $-.497^{* *}$ \\
\hline \multirow{2}{*}{ ON } & $\begin{array}{l}\text { Teak } \\
\text { NDVI }\end{array}$ & 0.332 & $.642^{* *}$ & $.551^{* *}$ & 0.296 \\
\cline { 2 - 6 } & $\begin{array}{l}\text { Sal } \\
\text { NDVI }\end{array}$ & 0.213 & $.588^{* *}$ & $.499^{* *}$ & 0.327 \\
\hline
\end{tabular}

\section{CONCLUSION}

The analysis of past climate data for 45 years (1971-2015) of STR showed a significant increasing trend of mean temperature. However, the trend of rainfall and number of rainy days over the same period followed irregular pattern with no trend. The NDVI is a potential tool to monitor forest health and infer seasonal dynamics. The recent literature shows that EVI is a better indicator than NDVI for assessment of high biomass vegetation (Chang et al, 2014; Heute at el, 2002). The annual NDVI for both Teak and Sal landscape showed an increasing trend for the period 2000-2015. The NDVI value extracted for Teak and Sal forest in STR for the period between 2000 to 2015 showed that Sal dominated forest had the maximum values in all the study years in comparison of Teak forest. Furthermore, the mean annual NDVI and mean annual temperature increased significantly over the period 2000-2015. Based on correlation analysis, the study concludes that both the species are sensitive to change in temperature with Sal more sensitive to mean temperature, whereas Teak is more sensitive to change in maximum temperature. However, it needs further research using high-resolution remote sensing data and ground data for validation. Further, at the species level, hyperspectral data holds immense potential in distinguishing different vegetation on the ground. The time series analysis clearly indicated that temperature is a major influencing factor in the NDVI as 
compared to rainfall. To establish a clear understanding of the causal relationship between NDVI and climate variables, the use of other health indicators like EVI is recommended especially in high canopy areas.

\section{REFERENCES}

Bachelet, D., R. P. Neilson, J. M. Lenihan, and P. J. Drapek. 2001. "Climatic Change Effects on Vegetation Distribution and Carbon Budget in the United States." Ecosystems (4)3: 164-185.

Beck, P. S. A., Jönsson, P., Høgda, K. A., Karlsen, S. R.,Eklundh, L., \& Skidmore, A. K. 2007FBECK. A groundvalidated NDVI dataset for monitoring vegetation dynamics and mapping phenology in Fennoscandia and the Kola peninsula. International Journal of Remote Sensing, 28(19), 4311-4330.

Bellassen, V. \& Luyssaert, S. 2014. Carbon sequestration: Managing forests in uncertain times. Nature, 506(7487), 153155.

Betts, R. A., Malhi, Y., \& Roberts, J. T. 2008. The future of the Amazon: new perspectives from climate, ecosystem and social sciences.Philosophical Transactions of the Royal Society B: Biological Sciences,363(1498), 1729-1735.

Chang, C.T., Wang, H.C., and Huang, C.Y., 2014. Retrieving multi-scale climatic variations from high dimensional timeseries MODIS green vegetation cover in a tropical/subtropical mountainous Island. Journal of Mountain Science, 11(2), pp. 407-420.

Dasgupta, S., Laplante, B., Murray, S., \& Wheeler, D. 2009. Climate change and the future impacts of storm-surge disasters in developing countries. Center for Global Development Working Paper, (182).

Fitter, A. H., Fitter, R. S. R., Harris, I. T. B., \& Williamson, M. H. 1995. Relationships between first flowering date and temperature in the flora of a locality in central England. Functional Ecology, 55-60.

Guo, Z. X., Wang, Z. M., Song, K. S., Zhang, B., Li, F., \& Liu, D. W. 2007. Correlations between forest vegetation NDVI and water/thermal condition in Northeast China forest regions in 1982-2003. Chinese Journal of Ecology,26(12), 1930-1936.

Hänninen, H. 2006) Climate warming and the risk of frost damage to boreal forest trees: identification of critical ecophysiological traits. Tree physiology,26(7), 889-898.

Hansen, J., Ruedy, R., Sato, M., \& Lo, K. 2010. Global surface temperature change. Reviews of Geophysics, 48(4).

Hao, F., Zhang, X., Ouyang, W., Skidmore, A. K., \& Toxopeus, A. G. 2012. Vegetation NDVI linked to temperature and precipitation in the upper catchments of Yellow River. Environmental Modeling \& Assessment, 17(4), 389-398.

IPCC, 2007.Climate Change 2007: Impacts, Adaptation and Vulnerability. Contribution of Working Group II to the Fourth
Assessment Report of the Intergovernmental Panel on Climate Change.

Justice, C. O., Vermote, E., Townshend, J. R., Defries, R., Roy, D. P., Hall, D. K., ... \& Lucht, W. 1998. The Moderate Resolution Imaging Spectroradiometer (MODIS): Land remote sensing for global change research. IEEE transactions on geoscience and remote sensing, 36(4), 1228-1249.

Kaser, G., Hardy, D. R., Molg, T., Bradley, R. S., \& Hyera, T. M. 2004. Modern glacier retreat on Kilimanjaro as evidence of climate change: observations and facts. International journal of Climatology, (24), 329-339.

Kasischke, E. S., \& French, N. H. 1995. Locating and estimating the areal extent of wildfires in Alaskan boreal forests using multiple-season AVHRR NDVI composite data. Remote Sensing of Environment, 51(2), 263-275.

Kawabata, A., K. Ichii, and Y. Yamaguchi. 2001. "Global Monitoring of Interannual Changes in Vegetation Activities Using NDVI and Its Relationships to Temperature and Precipitation." International Journal of Remote Sensing 22 (7): 1377-1382.

Nischitha, V., Ahmed, S. A., Varikoden, H., \& Revadekar, J. V. 2014. The impact of seasonal rainfall variability on NDVI in the Tunga and Bhadra river basins, Karnataka, India. International journal of remote sensing, 35(23), 8025-8043.

Parry, Canziani M L, Palutikof O F et al. (Eds.), Cambridge University Press, Cambridge, UK, 976.

Pettorelli, N., Vik, J. O., Mysterud, A., Gaillard, J. M., Tucker, C. J., \& Stenseth, N. C. 2005. Using the satellite-derived NDVI to assess ecological responses to environmental change. Trends in ecology \& evolution, 20(9), 503-510.

Sarmah, S., Jia, G., \& Zhang, A. 2018. Satellite view of seasonal greenness trends and controls in South Asia. Environmental Research Letters, 13(3), 034026.

Schär, C., \& Jendritzky, G. 2004. Climate change: hot news from summer 2003. Nature, 432(7017), 559-560.

Schultz, P. A., and M. S. Halpert. 1995. "Global Analysis of the Relationships among a Vegetation Index, Precipitation and Land Surface Temperature. ” International Journal of Remote Sensing

Singh, K. P., \& Kushwaha, C. P. 2005. Diversity of flowering and fruiting phenology of trees in a tropical deciduous forest in India. Annals of Botany, 97(2), 265-276.

Song, Y., and M. G. Ma. 2011. "A Statistical Analysis of the Relationship between Climatic Factors and the Normalized Difference Vegetation Index in China." International Journal of Remote Sensing 32 (14): 3947-3965.

Spanner, M. A., L. L. Pierce, S. W. Running, and D. L.Peterson. 1990. "The Seasonality of AVHRR Data of Temperature Coniferous Forests: Relation to Leaf Area Index." Remote Sensing of Environment 33 (2): 97-112. 
Spanner, M. A., Pierce, L. L., Running, S. W., \& Peterson, D. L. 1990. The seasonality of AVHRR data of temperate coniferous forests: relationship with leaf area index. Remote Sensing of environment, 33(2), 97-112.

Stern, N. 2007. The economics of climate change: the Stern review. Cambridge University press.

Suzuki, R., J. Q. Xu, and K. Motoya. 2006. "Global Analyses of Satellite-Derived Vegetation Index Related to Climatological Wetness and Warmth." International Journal of Climatology 26 (4): 425-438. 16 (15): 2755-2577.

Van Leeuwen, W. J., Orr, B. J., Marsh, S. E., \& Herrmann, S. M. 2006. Multi-sensor NDVI data continuity: Uncertainties and implications for vegetation monitoring applications. Remote sensing of environment, 100(1), 67-81.

Yang, J., Guo, N., \& Jia, J. H. 2007. Comparison between MODIS/NDVI and MODIS/EVI in northwest china. Arid Meteorology, 25(1), 38-43. 